\title{
Study on the Influence of Coach's Sense of Work Alienation on Job Performance
}

\author{
Long Liu \\ Panyapiwat Institute of Management \\ Bangkok, Thailand \\ 2008liulong0808@163.com
}

\begin{abstract}
The development and scale of campus basketball in China directly determines the basketball talent training of China in the future, therefore, in an increasingly competitive environment, the management and work efficiency of coaches are especially important! This paper selected 112 universities in China and issued 437 questionnaire, however, 381 responded to the questionnaire. The result shows: the coach's sense of alienation is at a moderate level, and self-alienation is higher than relational alienation and environmental alienation; the emergence of a sense of alienation in work will lead to lower work performance and cause demission; and the reduction of work alienation can improve work performance and reduce all kinds of negative work behaviors in managerial psychology and behavioral theories, which can improve organizational management and performance of coaches, stimulate teachers' enthusiasm for work, avoid negative emotions, improve work efficiency and train more basketball talents.
\end{abstract}

Keywords - coach; job performance; work alienation; influence

\section{PROBLEM PRESENTATION}

How many world-class athletes a country can produce depends on how many world-class coaches the country has. Therefore, a coach is one of the important factors to realize the plan of winning an Olympic Games, and it plays a leading role in the whole process of sports training. Thus, coaches' psychological health and organizational management ability and working environment are particularly important.

the reality is greater, which causes the state of being separated from work among coaches. The earliest discussion of work alienation can be traced back to Marx, he once pointed out that separation of workers from ownership and the loss of control on the fruits of labor would lead to alienation of labor when he expounded the nature of capitalism. Korman, Wittig-Berman, and Lang (1981) [4] argue that work alienation has become a common phenomenon in all fields of work life and permeates. Therefore, paying attention to sports coaches' mental health and job performance are closely related, so the research work alienation of the impact on the performance of college basketball coaches perhaps open the work force of the black box, promoting the efficiency of training coaches in

\footnotetext{
*Corresponding author
}

physical education teaching and training to raise professional sports talents

\section{CORRELATION STUDIES}

The sense of alienation from work is not a new academic concept, it was studied for many years earlier in European and American countries. However, from the relevant literature of China's domestic researches, the study of alienation of work began since 2005. Scholars mainly focused on the concepts and literature review, while relevant empirical studies mainly focused on researches of alienation in work of knowledge workers, hospital nurse work area and students learning alienation. Relevant literature researches showed that the negative consequences of job alienation mainly affected work performance, work attitude and work behavior, while studies on the mental health and job performance of college teachers mainly focused on job stress, career confusion, etc. As known, physique of Chinese college students and middle school students has been declining in recent 25 years, which is related to educational system. But, it is also related to the working condition and working environment of the majority of the sports workers, especially the physical education teachers. Therefore, through empirical research, this paper analyzes the alienation caused by job stress, environmental pressure and relationship pressure of college sports coaches, so as to explore the relationship between work alienation and job performance.

\section{RESEARCH TOOLS AND RESEARCH METHODS}

\section{A. Subject investigated}

Subject investigated by this paper was basketball coaches in Colleges and universities. A total of 437 questionnaires have been issued throughout the country, with 412 returned. After sorting and screening, 31 copies of invalid questionnaires excluded, there are 381 valid questionnaires collected in total finally, with effective rate reaching $85.2 \%$. The valid data of these 381 questionnaires mainly come from the questionnaire survey of more than 200 colleges and universities all over the country, involving 112 colleges and universities departments. Among the valid questionnaires, of which $80.01 \%$ are men and $19.99 \%$ are women, and $16.27 \%$ under 25 years old, $25.46 \%$ between 26 and 35 years old, $30.45 .5 \%$ between 36 and 45 years old, 
and $27.82 \%$ over 45 years old, $23.88 \%$ unmarried and $72.12 \%$ married. What's more, $0 \%$ of them are with college degree or below; bachelor degree $24.67 \%$, master degree or equivalent $75.33 \%$. When comes to working life, 122 people's (32.02\%) are below 5 years; $41.99 \%$ between 6 and 10 years; $20.73 \%$ between 11 and 15 years; $4.72 \%$ between 16 and 20 years, and $0.05 \%$ over 30 years. And $9.19 \%$ are junior titles, $43.30 \%$ are middle-level titles, $28.87 \%$ are vice senior titles, and $18.64 \%$ for senior titles. $23.84 \%$ are from key universities in provincial capitals, 38.95\% non-key universities of the provincial capitals, $4.65 \%$ local key universities, and $32.56 \%$ local non-key colleges and universities.

\section{B. Research tool}

Mature localization questionnaire used by domestic researchers is adopted.

(1) Work alienation questionnaire: local combined Three factor scale proposed by Long Lirong (2014) [5], Wang Yuexin (2006) [6] is adopted, as well as Likert 5 point scoring, if scores are large, it indicates a strong sense of alienation. After examination, the value is 0.81., which conforms to the standard.

(2) Job performance questionnaire scale, the scale proposed by Williams \& Anderson (1991) [1] and Van Scotter \& Motowidlo (1996) [2] is adopted, as well as Likert 5 point scoring, the higher the score, the higher the probability of leaving, and after examination, the a value is 0.73 .

\section{FINDINGS}

\section{A. Descriptive statistical features on work alienation of college basketball coaching staff}

TABLE I. DESCRIPTIVE STATISTICAL FEATURES ON WORK Alienation of College Basketball Coaching StafF

\begin{tabular}{lcccc} 
Independent variables & Standard deviation & Mean & Min value & Max value \\
\hline Self alienation & 2.658 & 0.898 & 1 & 5 \\
Alienation of relationship & 1.790 & 0.711 & 1 & 5 \\
Environmental alienation & 2.625 & 0.902 & 1 & 5 \\
Work alienation & 2.400 & 0.496 & 1 & 5
\end{tabular}

From the above table, it can be seen that the general average of the alienated work of college basketball coaches is 2.368 , the standard deviation is 0.751 , according to the average on work alienation of the basketball coaching staff from different dimensions, work alienation of the coaching staff is the largest, followed by interpersonal relation.

\section{B. General situation of the work performance of college basketball coaching stall}

TABLE II. DEscriptive Statistics ON WORK PERFormanCE OF College Basketball CoAching StafF

$\begin{array}{lcccc}\text { Variables } & \text { Mean } & \text { Standard deviation } & \text { Min value } & \text { Max valu } \\ \text { Task performance } & 3.562 & 0.681 & 1 & 5 \\ \text { Relation performance } & 3.690 & 0.712 & 1 & 5 \\ \text { Work performance } & 3.722 & 0.676 & 1 & 5\end{array}$

As is shown in above table, the overall average performance of college basketball coaches and coaches is 3.658 , and the standard deviation is 0.690 . In the dimension of job performance, relation performance promotion is the highest, followed by task performance. All are in line with the trend of development of the times.

Regression analysis of alienation on work performance

(1) Regression analysis of work alienation from different dimensions on work performance

Hierarchical regression method is used to study the influence of independent variables on dependent variables. The results show that the analysis results will be scientific and reasonable after adding demographic control variables. Specific analysis results are shown below:

TABLE III. REGRESSION ANALYSIS ON THE INFLUENCE OF WORK ALIENATION ON TASK PERFORMANCE

\begin{tabular}{lll}
\hline \multicolumn{1}{c}{ Dependent variables } & \multicolumn{2}{c}{ Task performance } \\
& M1 & M2 \\
\hline Controlled variables & & -0.057 \\
Gender & -0.038 & $0.140^{* *}$ \\
Age & $0.135^{* *}$ & -0.0059 \\
Education & 0.071 & 0.088 \\
Working life & 0.061 & 0.030 \\
Mariage & -0.052 & 0.011 \\
Title & 0.049 & \\
Independent variables & & $0.263^{* *}$ \\
Self alienation & & $-0.152^{* *}$ \\
Alienation of relationship & & $0.139^{* *}$ \\
Environmental alienation & & 0.188 \\
$\quad$ R2 & 0.039 & $8.987^{* *}$ \\
$\quad \mathrm{~F}$ & $3.550^{* *}$ & 0.143 \\
$\quad \triangle \mathrm{R} 2$ & 0.040 & $16.100^{* *}$ \\
$\quad \triangle \mathrm{F}$ & $3.587^{* *}$ &
\end{tabular}

As is seen from table 3, control variables have explained $4 \%$ of variance in task performance, and the 3 dimension of the sense of alienation in work has explained $14.3 \%$ variance in task performance, while the $\mathrm{F}$ test has showed that the explanatory variable has a significant effect on the dependent variable. The 3 dimension of work alienation has influence on task performance. Deep analysis has revealed that the sense of alienation in work mainly refers to the negative effects of tasks and workloads on work, the heavy work load is from the large alienation of the work itself, but it is also due to heavy workload. The quantity of work is large and demands are high. Therefore, it can show better task performance, and for coaches who require higher selfemployment. Only in accordance with the requirements of school leaders to complete mission performance, can they reflect self-worth. Therefore, alienation positively influences task performance, environmental alienation refers to the 
psychological reaction caused by unreasonable arrangements and abnormal procedures in the work. As the saying goes, we cannot change this environment, we can only change ourselves to reflect the outstanding task performance.

(2) Regression analysis of work alienation at all dimensions on relationship performance

On the basis of introducing control variables, the independent variable is the 3 dimension of work alienation; the dependent variable is the contextual performance dimension in job performance. The specific results of regression analysis are as follows:

TABLE IV. REGRESSION ANALYSIS OF INFLUENCE OF WORK ALIENATION ON RELATIONSHIP PERFORMANCE ON RELATIONSHIP PERFORMANCE

\begin{tabular}{llc}
\hline Dependent variables & \multicolumn{2}{c}{ Relationship performance } \\
& $\mathrm{M} 1$ & $\mathrm{M} 2$ \\
\hline Controlled variables & & -0.043 \\
Gender & -0.066 & $0.210^{* *}$ \\
Age & $0.263^{* *}$ & -0.027 \\
Education & 0.029 & -0.058 \\
Working life & -0.068 & 0.038 \\
Marriage & -0.069 & 0.029 \\
Title & 0.059 & \\
Independent variables & & $0.260^{* *}$ \\
Self alienation & & $-0.069^{* *}$ \\
Alienation of relationship & & $0.098^{* *}$ \\
Environmental alienation & & 0.139 \\
$\quad \mathrm{R} 2$ & 0.042 & $6.690^{* *}$ \\
$\quad \mathrm{~F}$ & $3.520^{* *}$ & 0.101 \\
$\triangle \mathrm{R} 2$ & 0.032 & $9.003 * *$ \\
$\triangle \mathrm{F}$ & $3.501^{* *}$ &
\end{tabular}

As is seen from table 4 , the controlled variables have explained $3.2 \%$ of variance in relationship performance, the 3 dimensions of the sense of alienation in work based on this has explained $10 \%$ of variance in relational performance. This is the special contribution of task alienation to the task performance in the 3 dimension, by the $F$ test, it can explain the influence of independent variables on dependent variables. The 3 dimensions of work alienation has influence on relationship performance. The influence of the explanatory variable on the dependent variable is significant.

The effects of work self-alienation and relationship performance are positive. The promotion influence of relational alienation on contextual performance is negativegoing. However, there is no significant influence on the promotion in environment alienation and relationship performance. The reason is that the tasks and workloads of college teachers are heavy, alienation from the work itself is intense. When the work has a strong sense of alienation, it is necessary to improve the working environment and reduce the friction in the work, which is conducive to the completion of the task performance. And in the relationship between alienation and job performance, that is, the greater the sense of alienation, the lower the job performance. Therefore, improving interpersonal relationships can also promote job performance.

\section{RESEARCH IMPLICATION OF THE RELATIONSHIP BETWEEN WORK ALIENATION AND JOB PERFORMANCE}

Based on previous research, this paper finds that the sense of work alienation does exist in the work. The study has found that the influence of different dimensions of work alienation on job performance are different, and there are significant differences. The more job input, the better the task performance. The relationship performance may be lowered to affect the relationship between family and related interests, even physical health.

Through literature, the influence mechanism of work alienation on job performance is also affected by many variables. The work of a basketball coach is a dynamic one. It is a process of constant change for material selection, training, competition, management, competitors. Under equal pressure, the work alienation is different under different days, places, relationships. This is the key and difficult problem in the field of competitive sports. The sense of work alienation and its impact on job performance is a more complex systemic impact, which involves numerous mediating and moderating variables. The simple analysis of the effect of alienation on work performance may not eventually solve the problem of coaches. Therefore, the effects of various mediation and moderator variables are taken into account. A combination of longitudinal and horizontal research design is adopted to further derive the causal relationship between variables.

The main measure of the ability of coaches is achievement, and the main factors that affect the achievements are the opponent and competition environment factors (time, place, weather, referee, host and guest and so on), personal factors (physical, family factors, etc.), objective factors that belong to big blow to coaches. In fact, there are some mistakes in evaluating the performance of basketball coaches. Because team performance is not solely decided by a coach, it is a multiple product under multiple conditions. At present, the evaluation system of coaches in multi colleges and universities is too single. Therefore, we should set up a special evaluation system for coaches, the whole process from enrollment to graduation should be incorporated into the system, and achievements shall be combined with titles, income and right to speak. From the perspective of management, it is a quantization equilibrium process from planning of coach management process, selection and recruitment, performance and assessment, titles, salary and support, training and development. Therefore, a scientific management system for intervention, regulation on coaching staff are hence required to be established.

\section{ACKNOWLEDGMENT}

This paper is supported by Professor Hua Guowei, Beijing Jiaotong University and Dr. Udamber, thanks the 437 teachers for information and helps, thanks for Professor Hua.

\section{REFERENCES}

[1] H. Zhou, and L.R. Long "A review of research on work alienation," dvances in psychological science, vol. 1, 2011, pp. 117-123. 
[2] China 2010-2020 National plan for medium and long term education reform and development. July 2010

[3] M.J. Tian, "Wu Fuquan.Scientific exploration of sports," Beijing: People's Sports Publishing House, 1988, pp. 102-120.

[4] A.K. Korman, U. Wittig-Berman, and D. Lang, "Career success and personal failure: alienation in professionals and managers," Acad. Manage, vol. 24, 1981, pp. 342-361.
[5] L.R. Long, P.P. Mao, "'The influence of paternalistic leadership under mediating effect of organizational support on employee work alienation," Journal of management, pp. 1150-1157, Augest 2014.

[6] Y.X. Wang, "Component factors and related research of Chinese employees' sense of alienation," Department of education, Jinan University, May 2006. 